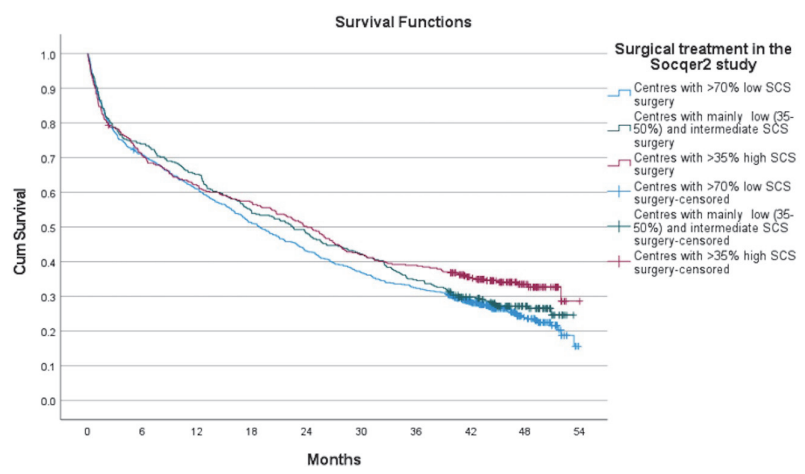

Abstract 718 Figure 1 Kaplan Meir Survival curve. Log rank test $\mathrm{p}=0.051$

Methodology The SOCQER2 study investigated quality of life after surgery of varying complexity for AOC in a prospective multicenter cohort study, recruiting for 12 months with 24 months follow-up. Results of QoL and variation in Surgical Complexity Scores (SCS) have been previously reported. ${ }^{2}$ SOCQER2 centers diverged in approach to URS; used routinely in some participating centers and not in others. Here we analyzed data from nationally collected datasets (Cancer Outcome and Services Data, Systemic Anti-Cancer Treatment, Hospital Episode Statistics) to investigate survival and treatment outcomes in the total cohort of patients from the cancer centers that participated in the SOCQER 2 study, including patients with FIGO Stage 3,4, and stage unknown AOC patients. Residual disease post-surgery was not available for analysis.

Result(s)* 1521 patients across 11 participating centers clustered into 3 groups - centers performing $>70 \%$ low SCS (5/ 11), mainly intermediate SCS $>40 \%(3 / 11)$ and mainly high SCS surgery $>35 \%$ (3/11) with 788, 365 and 368 patients. The proportion of patients receiving standard of care, surgery and chemotherapy, was similar in both low and high SCS groups and highest in the intermediate group (39.2 vs 38.3 vs $51.8, \mathrm{p}<0.000$ ) (table 1). Median survival was 24.0 vs 22.4 vs 18.8 months in the high, intermediate and low SCS centers, log rank test $\mathrm{p}=0.051$, (figure 1 ).

Conclusion* This multicenter ' real-life' population based study finds that URS does not reduce the proportion of AOC patients treated surgically. Centers with mainly intermediate SCS have higher proportion receiving surgery and chemotherapy; this may reflect a willingness to accept greater optimal rather than complete cytoreduction rates. Centers with greater radicality trend towards improved survival, but this did not reach statistical significance. A larger population level study to identify ideal intermediate: high SCS ratios is urgently needed.

\section{YOLK SAC OVARIAN TUMOR, IS ALWAYS FERTILITY PRESERVATION POSSIBLE?, REPORT OF THREE CASES AND REVIEW OF LITERATURE}

${ }^{1} \mathrm{~F}$ Behnamfar*, ${ }^{1} \mathrm{M}$ Nazemi, ${ }^{2} \mathrm{~B}$ Mohamadi. 'Isfahan University of Medical Sciences, Women's oncology, Isfahan, Iran; 'Isfahan University of Medical Sciences, Pathology, Isfahan, Iran

\subsection{6/ijgc-2021-ESG0.453}

Introduction/Background* Yolk sac ovarian tumors are rare, 2]. Surgery is required for diagnosis, staging, and treatment. Yolk sac tumor was universally life-threatening before the development of combination chemotherapy. With the introduction of novel chemotherapeutic regimens,.especially adding cisplatin to combination therapies, prognosis of the patients reached excellent values, even for patients with advanced stages.

Methodology

Result(s)* Case 1:A 12 years old girl presented in march 2018 with complain of abdominal pain. The ultrasonography (US) showed a huge pelvic solid tumor . AFP level was high (1200 $\mathrm{mg} / \mathrm{ml})$.Right salpingoophorectomy and pelvic lymphadenectomy were done.Histopathology revealed Yolk sac tumor limited to the ovary. Rising of AFP happened four months after the surgery and normalization of the marker. Imaging showed no gross disease .She received 3 courses of (Bleomycin,Etoposide and Cisplatin) and has been in remission. Menses restarted after six months of the last course of chemotherapy.

Case 2:A 25 years old woman G2Ab1L1 presented in May 2016 with severe abdominal pain and distension. The abdominal ultrasonography showed a huge heterogeneous solid cystic lesion and free fluid. AFP level was $1000 \mathrm{mg} / \mathrm{ml}$..Laparotmy was done. Ruptured fragmented right ovarian tumor, hemoperitoneum and tumor involving omentum and appendix were found. Right salpingoophorectomy, omentectomy,appendectomy and tumor debulkimg was done. Histopathology revealed Yolk sac tumor She received four cycles of BEP . AFP level decreased to normal after the fourth cycle. She has been in remission, normally menstruating in the past five years.

Case 3:A 21 years old girl presented in Sepember 2020 with complain of abdominal pain. The ultrasonography (US) showed a large solid pelvic tumor originating from right adnexa . AFP level was high $(8700 \mathrm{mg} / \mathrm{ml} \mathrm{Rt}$ salpingoophorectomy, pelvic and paraaortic lymphadenectomy were done. Tumor was ruptured intraoperatively.

Histopathology report revealed Yolk sac tumor limited to ovary. She received 3 courses of BEP regimen. .Her menses resumed five monthes after the last chemotherapy course and has been in remission .

Conclusion* These cases remind us, in adolescence and young age with solid high AFP levels and rapidly growing ovarian mass, diagnosis of the Yolk sac tumor has to be kept in mind. Long term remission and preservation of fertility seem to be possible when definite surgery and lchemotherapy with BEP regimen is used.

\section{NEW ALGORITHM TO ASSESS THE RISK OF MALIGNANCY IN PREMENOPAUSAL PATIENTS WITH PELVIC MASS}

\begin{abstract}
${ }_{1,2} \mathrm{M}$ Katsyuba*, ${ }^{1} \mathrm{R}$ Khasanov, ${ }^{3} \mathrm{~T}$ Madzhidov, ${ }^{4} \mathrm{G}$ Usmanova, ${ }^{5} \mathrm{G}$ Muratova, ${ }^{4} \mathrm{~A}$ Akhmetzianova, ${ }^{2} \mathrm{G}$ Fakhrutdinova, ${ }^{1,2} \mathrm{~V}$ Terenteva, ${ }^{3} \mathrm{~A}$ Rakhimbekova. ${ }^{1}$ Kazan State Medical Academy - Branch Campus of the FSBEI FPE RMACPE MOH Russia, Oncology, Kazan, Russian Federation; ${ }^{2}$ Kazan Clinical Cancer Center, Gynecological Oncology, Kazan, Russian Federation; ${ }^{3}$ A.M. Butlerov Institute of Chemistry, Kazan Federal University, Kazan, Russian Federation; ${ }^{4}$ Kazan Clinical Cancer Center, Laboratory medicine, Kazan, Russian Federation; ${ }^{5}$ Kazan Federal University, International preparatory school, Kazan, Russian Federation
\end{abstract}

\subsection{6/ijgc-2021-ESGO.454}

Introduction/Background* Human epididimis protein 4 (HE4) has been reported as a promizing biomarker in the assessment of the risk of malignancy in patients, diagnosed with pelvic mass. Howewer, reference limits of HE4 do not provide clinically relevant discrimination between malignant and benign 